\title{
Application Of Thrombelastography (TEG) For Evaluation of Hypercoagulable State In Perioperative Period of Primary/Revision Total Hip Arthroplasty (THA)
}

\author{
Jianye Yang \\ The First Affiliated Hospital of Chongqing Medical University \\ Sizheng Zhu \\ The First Affiliated Hospital of Chongqing Medical University \\ Leilei Qin \\ The First Affiliated Hospital of Chongqing Medical University \\ Jiawei Wang \\ The First Affiliated Hospital of Chongqing Medical University \\ Jiaxing Huang \\ The First Affiliated Hospital of Chongqing Medical University \\ Feilong Li \\ Chongqing Dazu people's hospital \\ Xi Liang \\ The First Affiliated Hospital of Chongqing Medical University \\ Wei Huang \\ The First Affiliated Hospital of Chongqing Medical University \\ Xuan Gong \\ Chongqing Gereral Hospital \\ Ning Hu ( $\sim$ huncqjoint@yeah.net) \\ First Affiliated Hospital of Chongqing Medical University https://orcid.org/0000-0001-9933-5924
}

\section{Research article}

Keywords: Total Hip Arthroplasty (THA), thrombelastography (TEG), Orthopaedics, Pulmonary embolism (PE)

Posted Date: July 8th, 2020

DOI: https://doi.org/10.21203/rs.3.rs-40537/v1

License: (c) (i) This work is licensed under a Creative Commons Attribution 4.0 International License. Read Full License 


\section{Abstract}

Background: Questions remain, there are no optimal accurately monitoring methods to assess the changes of coagulability during the perioperative period of arthroplasty especially revision THA. The objective of this study is to evaluate the Hypercoagulable State In Perioperative Period Of Primary/Revision THA by using a novel technique-TEG.

Methods: A retrospective review was conducted on 333 consecutive patients who underwent primary THA (236) or revision THA (97) and received rivaroxaban anticoagulant therapy at a tertiary academic center. TEG parameters, TEG coagulation status, and incidence of thrombotic events were used for coagulation evaluation.

Results: Compared with primary THA, revision THA had consistent statistically significant shortened R times on Pre, POD 1, POD3, POD 5, and POD7 ( $<<0.05)$. And the revision THA had consistent statistically significant increased MA than primary THA on Pre, POD 1, POD3, POD 5, and POD7(P<0.05) (Fig.1b). Similarly, compared with primary THA, revision THA had consistent statistically significant increased $\mathrm{Cl}$ on Pre, POD 1, POD3, POD 5, and POD7( $<<0.05)$ (Fig.1c). Significant differences in the incidence of hypercoagulable status between revision THA and primary THA on POD 1, 3, 5, and 7 ( $\mathrm{P}<0.05)$ These results suggested that patients who received revision THA were significantly more likely with hypercoagulable states. The results of the multivariate logistics regression analysis showed that $\mathrm{R}, \mathrm{MA}, \mathrm{Cl}$, operation time, and blood transfusion rate were independent risk factors for patients with postoperative hypercoagulability $(P<0.05)$.

Conclusions: Compared with primary THA patients, revision THA patients have a higher incidence of hypercoagulation, which may be related to longer operation time, greater surgical trauma, more intraoperative blood loss, and higher blood transfusion rate. TEG is a sensitive method to detect the evaluation of coagulation in the perioperative period of primary/revision THA. R, MA, and $\mathrm{Cl}$ were independent risk factors for patients with postoperative hypercoagulability, Which is of great significance for predicting hypercoagulability. In addition, the use of rivaroxaban anticoagulation alone after THA cannot effectively reduce the incidence of postoperative hypercoagulability, especially platelet hypercoagulability and mixed hypercoagulability.

\section{Introduction}

Pulmonary embolism (PE) and deep vein thrombosis (DVT),collectively known as venous thromboembolic events (VTEs) $\square$ continue to be catastrophic complications in major orthopedic surgery.[1, 2] A study by Shahi et al. included a total of 1,762,496 TJAs showed that there was a higher incidence of VTE for revision THA than revision TKA and primary THA/TKA.[3] Several reasons for higher VTE incidence of revision THA had been reported as follows: prolonged operative time, more extensive surgical exposure, and soft tissue dissection, longer postoperative mobilization et al.[4-6] Furthermore, the incidence of VTE on revision TJA remained basically unchanged from 2008 to 2016.[7] On the other hand, the existing anticoagulation guidelines do not separately propose anticoagulation options for revision TJA. Therefore, surgeons often use more aggressive anticoagulation therapy for revision TJA patients, which may also lead to an increased risk of bleeding complications.[8] In conclusion, it is very important to reduce coagulation-related complications by balancing thrombosis and bleeding during perioperative anticoagulation therapy.

For perioperative coagulation management, it is very important to accurately and comprehensively monitor the changes in coagulation of patients. However, there are no optimal accurately monitoring methods to assess the changes of coagulability during the perioperative period of arthroplasty. Conventional coagulation tests can effectively reflect the cascading process of the body's coagulation and are widely used in clinics, but it doesn't identify overall dynamic clot formation in whole blood.[9] In contrast, thromboelastography (TEG), a sensitive test for the characterization of the clotting process in whole blood, provides a comprehensive assessment of platelet function, plasma factor activity, fibrin polymerization, and fibrinolysis[10,11]. Moreover, TEG can offer a comprehensive bedside analysis and immediate results[12,13]. Besides, TEG is potentially useful in predicting which patients will develop thromboembolic complications 
and abnormal bleeding[14-16]. However, to the best of our knowledge, there was no study published about the TEG use following revision THA.

Therefore, the objective of this study is to determine 1) Is revision THA associated with higher rates of hypercoagulable state? 2)Is TEG an effective method for monitoring coagulation? 3)What are the independent risk factors for Hypercoagulable State after revision/primary THA?

\section{Materials And Methods}

\subsection{Study design and patients}

This study was approved by the institutional ethical review board of The First Affiliated Hospital of Chongqing Medical University (NO.2018-028) and The research as part of our registered project on Chinese Clinical Trial Registry (ChiCTR1800017245). We retrospectively reviewed our institutional database for all patients who underwent THA from April 2014 to December 2018. Patients who underwent primary/revision THA were eligible for inclusion. Exclusion criteria were: 1) the patients had not undergone TEG evaluation, 2) previous history of Deep Vein Thrombosis (DVT) or pulmonary embolism (PE), 3) patients treated with thromboprophylaxis agents other than Rivaroxaban (including heparin, enoxaparin, aspirin, warfarin, inferior vena cava filters, or any combination of VTE prophylactic drugs), 4)patients not treated with tranexamic acid, 5)the patients who had thrombocytopenia, diagnosed with hemophilia or chronic bleeding problems (eg, peptic ulcer), or decreased liver function. 6)patients with moderate or severe anemia ( $\mathrm{Hb}<9 \mathrm{~g} / \mathrm{dL}), 7$ )patients who underwent simultaneous bilateral arthroplasty.8)incomplete medical records. Ultimately, 97 revision THA and 236 primary THA were analyzed. Patient consent was waived since there was no intervention related to therapy. All operations were performed by the same surgical team, which was led by the same senior surgeon.

\subsection{Perioperative management}

All patients received daily a combination of mechanical and chemical prophylaxis to prevent VTE. The patient received rivaroxaban anticoagulation within 24 hours after surgery. Patients received daily Rivaroxaban 10 mg and continued for 5 weeks postoperatively if there weren't any coagulation-related complications. Preoperatively, all patients received lowerextremity muscular training. Passive and active physiotherapy was initiated after anesthesia resolution. All patients received intermittent pneumatic stockings on the first day of postoperation. Post-operation, all patients received daily screenings for clinical symptoms and signs of VTE until discharge. All patients received weekly screenings for venous thromboembolism from discharge until 5 weeks after surgery. All patients received monthly screenings for venous thromboembolism from 5 weeks to 3moth after surgery. In addition, patients received a doppler ultrasound immediately, if there was increased pain with leg swelling and a tense, tender calf, pretibial tenderness, and a positive Homans' test. Chest computed tomography (CT) angiography was performed immediately when PE was suspected clinically (shortness of breath, chest pain, lightheadedness, or chest congestion).

Criteria for transfusion included: (1) the $\mathrm{Hb}$ level of the patients was < $70 \mathrm{~g} / \mathrm{L}$ regardless of accompanying symptoms; (2) any case of symptomatic anemia (such as light-headedness, presyncope and an alteration in mental status or palpitation) as decided by the senior orthopedic surgeon in the patients with a Hb level of 70 to $100 \mathrm{~g} / \mathrm{L}$.

\subsection{Outcome measurements}

Coagulation outcomes included TEG parameters, TEG coagulation status analysis, and incidence of VTE(PE,DVT and intramuscular venous thrombosis). All TEG test were routinely performed pre-operatively (Pre), postoperative day 1 (POD1), POD3, POD5, and POD7. In addition, we also collected the basic characteristics and surgical information of patients.

\subsection{Thromboelastography}


TEG was performed preoperatively and on postoperative days 1, 3, 5, and 7. All blood samples were used to standard citrated kaolin-activated TEGs, and the tests were performed using TEG® Hemostasis Analyzer, Model 5000 (Haemonetics Corporation, Braintree, MA, USA). All the TEG tests were carried out by experienced personnel. They conducted qualitycontrol checks of TEG according to the manufacturer's standard protocols. We recorded TEG values including $\mathrm{R}$ (reaction time), $\mathrm{K}$ (coagulation time), a (alpha angle), MA (maximum amplitude), $\mathrm{Cl}$ (coagulation index). The $\mathrm{R}$ value is the time taken from the beginning of the trace to the amplitude of $2 \mathrm{~mm}$, which reflects the time for the thrombin burst. The $\mathrm{k}$ value is measured the time of the amplitude from 2 to $20 \mathrm{~mm}$, which measures the speed of clot strengthening. The MA value is the greatest amplitude of the tracing, which measures the maximum strength of the clot. The $\nabla$ value is the Angle between horizontal line and the tangent to the curve drawn from the amplitude of $2 \mathrm{~mm}$, which is an indication of the rate of clot formation. The $\mathrm{Cl}$ value a computer calculated linear combination of $\mathrm{R}, \mathrm{K}, \mathrm{MA}$, and a values. And the manufacturer provides the computational formula: $\mathrm{Cl}=-0.6516 \mathrm{R}-0.3772 \mathrm{~K}+0.1224 \mathrm{MA}+0.0759 a-7.7922$. And TEG-

hypercoagulability was classified into three types[17]: (1) enzymatic hypercoagulability, $R<=5 \mathrm{~min}, \mathrm{MA}<=70 \mathrm{~mm}$; (2) platelet hypercoagulability, $\mathrm{R}>5 \mathrm{~min}, \mathrm{MA}>70 \mathrm{~mm}$; (3) mixed hypercoagulability: $\mathrm{R}<=5 \mathrm{~min}, \mathrm{MA}>70 \mathrm{~mm}$.

\subsection{Statistical analysis}

Normally distributed numerical variables were presented as means \pm standard deviation (SD), and categorical variables were presented as $\mathrm{n}(\%)$. A student's t-test was used to compare the means of normally distributed numerical variables. Wilcoxon Mann-Whitney U test was used for non-normal distribution or unequal variance numerical variables. The proportion of categorical data was compared using $\chi 2$ tests or Fisher's exact test where appropriate. Multivariate Logistics regression analysis for analysis of independent risk factors of hypercoagulability. For all analyses $P$ values, less than 0.05 were interpreted as statistically significant. All statistical tests were performed using IBM SPSS Statistics 24.0 and Microsoft Excel 2016.

\section{Results}

\subsection{Patients characteristics}

There are 333 patients(97 revision THA, 236 primary THA) who were eligible for the study. Baseline clinical characteristics, Surgery information, and demographics of the patients were shown in Table 1. There was no significant difference between the revision THA and primary THA with respect to age, gender, BMI, smoking history, and medical comorbidities. But the revision THA was longer operation time than primary THA $(169.92 \pm 56.76 \mathrm{~min}$ VS $94.41 \pm 34.68 \mathrm{~min}, \mathrm{P}<0.01)$. Similarly, the intraoperative blood loss was significantly higher in revision THA than in primary THA $₫ 451.55 \pm 303.66 \mathrm{ml}$ VS $231.10 \pm 231.38 \mathrm{ml}, \mathrm{p}<0.01)$. In addition, revision THA had a higher incidence of transfusion than primary THA (48.45\% vs. $16.10 \%, p<0.01$ ). 
Table 1

Baseline clinical characteristics, Surgery information, and demographics for primary/revision THA.

\begin{tabular}{|llll|}
\hline & Revision THA(N = 97) & Primary THA(N= 236) & P \\
\hline Age(years) & $65.55 \pm 8.85$ & $64.17 \pm 15.15$ & 0.40 \\
\hline Gender (Male/Female) & & & \\
\hline Height(cm) & $160.70 \pm 6.44$ & $160.56 \pm 7.42$ & 0.87 \\
\hline Weight(Kg) & $59.45 \pm 9.10$ & $59.38 \pm 10.65$ & 0.94 \\
\hline BMI(Kg/m $\left.{ }^{2}\right)$ & $22.98 \pm 2.98$ & $22.95 \pm 3.30$ & 0.94 \\
\hline Intraoperative blood loss(ml) & $451.55 \pm 303.66$ & $231.10 \pm 231.38$ & $<0.01$ \\
\hline Operation time(min) & $169.92 \pm 56.76$ & $94.41 \pm 34.68$ & $<0.01$ \\
\hline Transfusion & $47(48.45 \%)$ & $38(16.10 \%)$ & $<0.01$ \\
\hline Smoking history & 35 & 78 & 0.60 \\
\hline Medical comorbidities & & & 0.63 \\
\hline Hypertension & 31 & 82 & 0.39 \\
\hline Diabetes mellitus & 39 & 107 & - \\
\hline Complications & & 0 & 0.86 \\
\hline DVT & 0 & 3 & \\
\hline PE & 0 & 0 & \\
\hline Intermuscular venous thrombosis & 1 & & \\
\hline
\end{tabular}

\subsection{Coagulation outcomes}

Compared with primary THA, revision THA had consistent statistically significant shortened R times on Pre, POD 1, POD3, POD 5, and POD7(Pre:5.88 $\pm 0.77 \mathrm{~min}$ VS $6.33 \pm 1.17 \mathrm{~min}$, POD 1: $4.43 \pm 1.06 \mathrm{~min}$ VS $4.78 \pm 1.16 \mathrm{~min}$, POD3: $4.65 \pm$ $1.18 \mathrm{~min}$ VS $4.98 \pm 0.87 \mathrm{~min}, \mathrm{POD} 5: 4.86 \pm 1.06 \mathrm{~min}$ VS $5.13 \pm 1.12 \mathrm{~min}, \mathrm{POD} 7: 4.96 \pm 0.94 \mathrm{~min}$ VS $5.24 \pm 1.13 \mathrm{~min}$, all $\mathrm{P}$ values were less than 0.05 ) (Fig. 1a). And the revision THA had consistent statistically significant increased MA than primary THA on Pre, POD 1, POD3, POD 5, and POD7(Pre:65.35 \pm 5.09 mm VS 63.08 \pm 7.66 mm, POD1: $64.90 \pm 8.03 \mathrm{~mm}$ VS $62.25 \pm 8.89 \mathrm{~mm}$, POD3: $69.01 \pm 6.30 \mathrm{~mm}$ VS $66.76 \mathrm{~mm}$, POD 5:70.64 $\pm 5.99 \mathrm{~mm}$ VS 68.45 $\pm 5.99 \mathrm{~mm}$, POD 7: $71.12 \pm$ $4.93 \mathrm{~mm}$ VS $68.46 \pm 6.77 \mathrm{~mm}$, all P values were less than 0.05) (Fig. 1b). Similarly, compared with primary THA, revision THA had consistent statistically significant increased Cl on Pre, POD 1, POD3, POD 5, and POD7(Pre: 1.22 \pm 1.32 VS $0.63 \pm$ 1.66 , POD 1: $1.97 \pm 1.48$ VS $1.42 \pm 1.71$, POD $3: 2.39 \pm 1.42$ VS $1.86 \pm 1.18$, POD 5: $2.67 \pm 1.28$ VS $2.27 \pm 1.30$, POD 7: 2.77 \pm 1.19 VS $2.19 \pm 1.71$, all $P$ values were less than 0.05 ) (Fig. 1c). These results suggested that patients who received revision THA were significantly more likely with hypercoagulable status. There was a significant decrease in $\mathrm{K}$ time in revision THA compared with primary THA on POD 7(1.17 \pm 0.47 min VS $1.37 \pm 0.58 \mathrm{~min}, \mathrm{P}=0.04)$ (Fig. $1 \mathrm{~d}$ ). In addition, there was a significant decrease in a angle in revision THA compared with primary THA on POD 3 and POD 7 (POD 3: $70.66^{\circ} \pm 6.55^{\circ}$ VS $68.03^{\circ} \pm 5.67^{\circ}$, POD $7: 72.97^{\circ} \pm 6.18^{\circ}$ VS $70.31^{\circ} \pm 7.65^{\circ}$, all P values were less than 0.01 ) (Fig. 1e)

The distribution of different hypercoagulable states between revision THA and primary THA are shown in Fig. 2. Significant differences in the incidence of hypercoagulable status between revision THA and primary THA on POD 1, 3, 5, and 7 (POD 1: 78.35\% VS 67.37\%, POD 3: 74.23\% VS 62.27\%, POD 5: 78.35\% VS 66.95\%, POD 7: 76.29\% VS 65.25\%, all P 
values were less than 0.05$)$, which suggested that patients who received revision THA were significantly more likely with hypercoagulable status. In addition, we also found that the incidence of postoperative hypercoagulation in the primary/revision THA patients did not decrease significantly with the extension of postoperative time, but the proportion of enzymatic hypercoagulation decreased significantly, while the proportion of platelet hypercoagulation and mixed hypercoagulation increased significantly (Table 2 ). These results indicate that rivaroxaban cannot effectively reduce the incidence of perioperative hypercoagulability, especially platelet hypercoagulability and mixed hypercoagulability. The incidence of intramuscular venous thrombosis was $1.27 \%$ for primary THA and $1.03 \%$ for revision THA $(P=0.86)($ Table 1$)$.

Table 2

The proportion of different statuses of coagulability at postoperation day 7 of revision THA and primary THA. POD1 post-operative day 1, POD7 postoperative day 7.

\begin{tabular}{|c|c|c|c|c|c|c|}
\hline & \multicolumn{3}{|c|}{ Revision THA } & \multicolumn{3}{|c|}{ Primary THA } \\
\hline & POD 1 & POD 7 & $\mathrm{P}$ & POD 1 & POD 7 & $\mathrm{P}$ \\
\hline Normal & 21 & 23 & \multirow[t]{4}{*}{$P<0.01$} & 77 & 82 & \multirow[t]{4}{*}{$P<0.01$} \\
\hline Enzymatic hypercoagulability & 47 & 10 & & 87 & 19 & \\
\hline Platelet hypercoagulability & 17 & 26 & & 37 & 63 & \\
\hline Mixed hypercoagulability & 12 & 38 & & 35 & 72 & \\
\hline
\end{tabular}

\subsection{Risk Factors Analysis of Hypercoagulable State}

We take patients with hypercoagulation after surgery as a hypercoagulation group (revision THA: 76,primary THA囚159) and patients without hypercoagulation after surgery as a control group (revision THA囚76囚primary THA囚159). Univariate analysis of common risk factors showed that preoperative $\mathrm{R}, \mathrm{MA}, \mathrm{Cl}$, age, operation time, and blood transfusion rate were closely related to the occurrence of postoperative hypercoagulable state, and the difference was statistically significant ( $P$ $<0.05$ ) (Table 3). There was no significant difference in $\mathrm{K}$ value, a, BMI, intraoperative bleeding, hypertension, and diabetes before operation $(\mathrm{P}>0.05$ ) (Table 3). Therefore, we further included $\mathrm{R}, \mathrm{MA}, \mathrm{Cl}$, age, operation time, and blood transfusion rate into multivariate logistics regression analysis. The results showed that $\mathrm{R}, \mathrm{MA}, \mathrm{Cl}$, operation time, and blood transfusion rate were independent risk factors for patients with postoperative hypercoagulability $(P<0.05)($ Table 4$)$. 
Table 3

Univariate analysis of common risk factors for revision/primary THA. TEG thromboelastography, THA total hip arthroplasty.

\begin{tabular}{|c|c|c|c|c|c|c|}
\hline & Revision THA & & & Primary $\mathrm{Tr}$ & & \\
\hline TEG at preoperation & Hypercoagulation(76) & Control(21) & $\mathrm{P}$ & Hypercoagulation(159) & Control(77) & $\mathrm{P}$ \\
\hline $\mathrm{R}(\min )$ & $5.79 \pm 0.74$ & $6.20 \pm 0.81$ & 0.03 & $6.07 \pm 1.17$ & $6.88 \pm 0.96$ & $\begin{array}{l}< \\
0.01\end{array}$ \\
\hline $\mathrm{K}(\mathrm{min})$ & $1.41 \pm 0.47$ & $1.56 \pm 0.52$ & 0.24 & $1.32 \pm 0.45$ & $1.37 \pm 0.41$ & 0.46 \\
\hline$a\left(^{\circ}\right)$ & $68.05 \pm 11.76$ & $\begin{array}{l}68.10 \pm \\
6.89\end{array}$ & 0.99 & $67.90 \pm 6.66$ & $\begin{array}{l}66.88 \pm \\
6.42\end{array}$ & 0.27 \\
\hline $\mathrm{MA}(\mathrm{mm})$ & $67.06 \pm 3.06$ & $\begin{array}{l}59.13 \pm \\
5.36\end{array}$ & $\begin{array}{l}< \\
0.01\end{array}$ & $65.79 \pm 6.93$ & $\begin{array}{l}59.57 \pm \\
7.92\end{array}$ & $\begin{array}{l}< \\
0.01\end{array}$ \\
\hline $\mathrm{Cl}$ & $1.49 \pm 1.29$ & $0.23 \pm 0.87$ & $<0.01$ & $1.10 \pm 1.60$ & $\begin{array}{l}-0.34 \pm \\
1.50\end{array}$ & $\begin{array}{l}< \\
0.01\end{array}$ \\
\hline Age(years) & $66.80 \pm 8.23$ & $\begin{array}{l}61.00 \pm \\
9.67\end{array}$ & $\begin{array}{l}< \\
0.01\end{array}$ & $65.26 \pm 15.56$ & $\begin{array}{l}60.92 \pm \\
14.10\end{array}$ & 0.04 \\
\hline $\mathrm{BMI}(\mathrm{Kg} / \mathrm{m} 2)$ & $22.98 \pm 3.01$ & $\begin{array}{l}22.96 \pm \\
2.91\end{array}$ & 0.98 & $22.88 \pm 3.29$ & $\begin{array}{l}23.08 \pm \\
3.34\end{array}$ & 0.67 \\
\hline Operation time(min) & $177.41 \pm 59.38$ & $\begin{array}{l}142.81 \pm \\
35.45\end{array}$ & 0.01 & $97.70 \pm 34.92$ & $\begin{array}{l}87.61 \pm \\
33.39\end{array}$ & 0.04 \\
\hline $\begin{array}{l}\text { Intraoperative blood } \\
\text { loss(ml) }\end{array}$ & $475.00 \pm 323.6$ & $\begin{array}{l}366.67 \pm \\
202.69\end{array}$ & 0.13 & $215.22 \pm 210.87$ & $\begin{array}{l}263.90 \pm \\
267.37\end{array}$ & 0.06 \\
\hline Transfusion(yes/no) & $41 / 35$ & $6 / 15$ & 0.02 & $31 / 128$ & $7 / 70$ & 0.04 \\
\hline Hypertension(yes/no) & $23 / 53$ & $8 / 13$ & 0.50 & $55 / 103$ & $27 / 50$ & 0.94 \\
\hline $\begin{array}{l}\text { Diabetes } \\
\text { mellitus(yes/no) }\end{array}$ & $27 / 49$ & $12 / 9$ & 0.07 & $73 / 83$ & $34 / 43$ & 0.70 \\
\hline
\end{tabular}

Table 4

multivariate logistics regression analysis of risk factors for revision/primary THA. THA total hip arthroplasty.

\begin{tabular}{|lllllll|}
\hline \multicolumn{1}{l}{ Revision THA } & \multicolumn{5}{l|}{ Primary THA } \\
\hline & OR & $95 \% \mathrm{Cl}$ & $\mathrm{P}$ & $\mathrm{OR}$ & $95 \% \mathrm{Cl}$ & $\mathrm{P}$ \\
\hline Age & 0.972 & $0.871-1.092$ & 0.594 & 0.983 & $0.963-1.011$ & 0.143 \\
\hline Operation time & 1.971 & $1.942-1.993$ & 0.014 & 0.990 & $0.985-1.000$ & 0.049 \\
\hline Incidence of transfusion & 5.354 & $1.057-11.952$ & 0.043 & 1.772 & $0.653-4.874$ & 0.021 \\
\hline $\mathrm{R}$ & 6.873 & $1.67-15.11$ & 0.003 & 3.621 & $1.963-6.717$ & $<0.001$ \\
\hline $\mathrm{MA}$ & 1.526 & $1.394-1.747$ & $<0.001$ & 1.799 & $1.712-1.898$ & $<0.001$ \\
\hline $\mathrm{Cl}$ & 1.257 & $1.066-2.585$ & 0.049 & 2.302 & $1.234-4.294$ & 0.009 \\
\hline
\end{tabular}

\section{Discussion}


In our study, the main finding included: 1) According to the monitoring results of TEG, in comparison with primary THA patients, revision THA patients were more prone to hypercoagulation on postoperation. 2) $\mathrm{R}, \mathrm{MA}, \mathrm{Cl}$ were independent risk factors for patients with a postoperative hypercoagulable state, indicating that TEG is important in predicting postoperative hypercoagulable state. 3) Rivaroxaban didn't effectively reduce the incidence of the postoperative hypercoagulable state.

Studies have shown that operation time is an independent risk factor for patients with thrombosis after surgery $[4,18]$. In our study, the operation time of the revision THA was significantly longer than the primary THA, which may be one of the reasons for the higher incidence of postoperative hypercoagulation. The main risk factors of hypercoagulability include sepsis, inflammation, blood stasis, the trauma of surgery, atherosclerosis, physical disruption of the endothelium, and it manifests selectively in thrombophilia. $[19,20]$ In our study, intraoperative blood loss and blood transfusion rates of the revision THA are higher than the primary THA, which means that the surgical trauma of the revision THA is greater, and the blood vessel wall damage and blood stasis of the revision THA are more serious. This may also be the reason for the higher incidence of hypercoagulation of revision THA. In addition, In a study by $\mathrm{Ng}$ et al, the development of a hypercoagulable state is related to mild to moderate degree of intraoperative blood loss[21]. In our study, intraoperative blood loss of the revision THA was significantly more than the primary THA, which may play a role in inducing hypercoagulable state. Red blood cell (RBC) transfusions may increase postoperative hypercoagulable state and surgery and perioperative RBC transfusions may have synergistic effects of increased related risk for VTE development[22]. The mechanism may be related to the submicron vesicles released during the storage of red blood cells. These particles have certain biological activities, which can lead to hypercoagulability in patients receiving a blood transfusion in a short time[23].All in all, in comparison with primary THA, the reasons for the higher incidence of hypercoagulation in revision THA include longer operation time, greater surgical trauma, more intraoperative blood loss, and higher blood transfusion rate.

In our study, R, MA, and $\mathrm{Cl}$ were independent risk factors for THA patients with postoperative hypercoagulability. Our study found consistent results with previous research. In 2005, a study by Douglas et al.[24]was the first time evidence was reported that demonstrated the association between hypercoagulability state measured by TEG and postoperative thromboembolic complications in surgical patients. And TEG is a useful adjunctive test for the assessment of thrombus, even if conventional coagulation screen methods were normal[13]. The results of an observational study suggest that an increase in $\mathrm{R}$ is associated with a decrease in the incidence of VTE, in contrast, a decrease in R indicates that patients tend to be hypercoagulable and the risk of DVT is higher[25]. Crath et al.[24] prospectively included 240 patients undergoing surgery and found that the increase in MA is closely related to the postoperative hypercoagulable state and thrombotic complications, and the risk of thrombotic complications in postoperative hypercoagulable patients is higher. The increase in MA value is As an important tool for identifying high-risk patients with thrombotic complications. In addition, the increased $\mathrm{Cl}$ value is a sensitive indicator for predicting postoperative hypercoagulable state and thrombotic complications, and can guide the perioperative anticoagulation scheme[13, 14, 24]. In summary, TEG is a sensitive method to detect the evaluation of coagulation in the perioperative period of primary/revision THA. And TEG is an effective indicator for predicting postoperative hypercoagulability in patients with THA.

In our institution, we routinely use rivaroxaban to prevent thrombosis. However, the incidence of postoperative hypercoagulation in the revision THA exceeded $70 \%$, and the incidence of postoperative hypercoagulation in the primary THA also exceeded $60 \%$. The previous study found rivaroxaban prolongs $\mathrm{R}$ and $\mathrm{K}$, while decreasing a angle and $\mathrm{MA}[26]$. Therefore the explanation for hypercoagulable state may be the recommended dose of rivaroxaban was insufficient or some patients are not sensitive to rivaroxaban. Rivaroxaban, an oral direct factor Xa inhibitor, been proven safe and efficacious. In 2020, a study of Hernandez-Juarez et al.[27] showed that even a high dose of rivaroxaban did not affect platelet aggregation. This may be the reason that the proportion of platelet hypercoagulation and mixed hypercoagulation increased significantly with the extension of postoperative time. In conclusion, the use of rivaroxaban anticoagulation 
alone after THA cannot effectively reduce the incidence of postoperative hypercoagulability, especially platelet hypercoagulability and mixed hypercoagulability. Among the chemopreventive drugs recommended by ACCP9, aspirin and low molecular weight heparin (LMWH) are in the same position as rivaroxaban[28]. Therefore, when clinicians choose anticoagulants, they tend to use them according to the routine of each center, and there is no uniform standard. Based on the results of this study, anticoagulation with rivaroxaban combined with antiplatelet drugs (such as aspirin) after THA may be an effective method to reduce the incidence of postoperative hypercoagulability. Of course, we need further research to verify its safety and effectiveness.

There are several limitations to this study. This is a retrospective study, which may be more susceptible to selection bias. Furthermore, a relatively small number of cases, short follow-up, and no routine Color Duplex ultrasound might have concealed the incidence rate of VTE or hypercoagulable state. Despite these limitations, we believe that our study is worth a presentation. Because, to our knowledge, only a handful of literature has reported coagulation monitoring by TEG following primary arthroplasty, but there is no data regarding TEG after revision THA. This is the first study that applied TEG to evaluate the coagulation of revision THA.

\section{Conclusions}

Compared with primary THA patients, revision THA patients have a higher incidence of hypercoagulation, which may be related to longer operation time, greater surgical trauma, more intraoperative blood loss, and higher blood transfusion rate. TEG is a sensitive method to detect the evaluation of coagulation in the perioperative period of primary/revision THA. R, $\mathrm{MA}$, and $\mathrm{Cl}$ were independent risk factors for patients with postoperative hypercoagulability, Which is of great significance for predicting hypercoagulability. In addition, the use of rivaroxaban anticoagulation alone after THA cannot effectively reduce the incidence of postoperative hypercoagulability, especially platelet hypercoagulability and mixed hypercoagulability.

\section{Abbreviations}

VTE: Venous thromboembolism event

THA: Total hip arthroplasty

TEG: Thromboelastography

POD: Postoperative day

AAOS: American Academy of Orthopaedic Surgeons

ACCP: American College of Chest Physicians

TJA: Total joint arthroplasty

DVT: Deep Vein Thrombosis

PE: Pulmonary embolism

\section{Declarations}

\section{Acknowledgements}


The authors thank Zheng-Lin Zhu,M.D.; Peng-Cheng Xiao, M.D.; Zhang-Yu Wang, M.D.; and Yu-Jian Li, M.D. (From Department of Orthopedic Surgery, The First Affiliated Hospital of Chongqing Medical University, Chongqing, China) for their substantial contribution in acquisition of data to this work; And Jianye Yang wants to thank, in particular, the patience, care and support from his parents and Sha Xu over the passed years.

\section{Ethics approval and consent to participate}

This study was approved by the institutional ethical review board of The First Affiliated Hospital of Chongqing Medical University (N0.2018-028). Patient consent was waived since there was no intervention related to therapy.

\section{Consent for publication}

Not applicable.

\section{Availability of data and materials}

The datasets used and/or analysed during the current study are available from the corresponding author on reasonable request.

\section{Competing interests}

The authors declare that they have no competing interests.

\section{Funding}

This work was supported by the research grant from the National Natural Science Foundation of China (NSFC), Grant number 81672167.

\section{Authors' contributions}

Jianye Yang: Contributed substantially to conception and design, acquisition of data, analysis, and interpretation of data; drafted the article; gave final approval of the version to be published; agreed to act as a guarantor of the work.

Sizheng Zhu: Contributed substantially to the acquisition and interpretation of data; revised it critically for important intellectual content; gave final approval of the version to be published; agreed to act as a guarantor of the work.

Leilei Qin:Contributed substantially to the acquisition and interpretation of data; revised it critically for important intellectual content; gave final approval of the version to be published; agreed to act as a guarantor of the work.

Jiawei Wang: Contributed substantially to the acquisition and interpretation of data; revised it critically for important intellectual content; gave final approval of the version to be published; agreed to act as a guarantor of the work.

Jiaxing Huang: Contributed substantially to the acquisition and interpretation of data; revised it critically for important intellectual content; gave final approval of the version to be published; agreed to act as a guarantor of the work. 
Feilong Li: Contributed substantially to the acquisition and interpretation of data; revised it critically for important intellectual content; gave final approval of the version to be published; agreed to act as a guarantor of the work.

Xi Liang: Contributed substantially to conception and design, acquisition of data, analysis, and interpretation of data; revised it critically for important intellectual content; gave final approval of the version to be published; agreed to act as a guarantor of the work.

Wei Huang: Contributed substantially to the acquisition and interpretation of data; revised it critically for important intellectual content; gave final approval of the version to be published; agreed to act as a guarantor of the work.

Xuan Gong: Contributed substantially to conception and design, acquisition of data, analysis, and interpretation of data; revised it critically for important intellectual content; gave final approval of the version to be published; agreed to act as a guarantor of the work.

Ning Hu: Contributed substantially to conception and design, acquisition of data, analysis, and interpretation of data; revised it critically for important intellectual content; gave final approval of the version to be published; agreed to act as a guarantor of the work.

\section{References}

1. Warren JA, Sundaram K, Anis HK, Kamath AF, Higuera CA, Piuzzi NS: Have Venous Thromboembolism Rates Decreased in Total Hip and Knee Arthroplasty? J Arthroplasty 2020, 35(1):259-264.

2. Landy DC, Bradley AT, King CA, Puri L: Stratifying Venous Thromboembolism Risk in Arthroplasty: Do High-Risk Patients Exist? J Arthroplasty 2020, 35(5):1390-1396.

3. Shahi A, Chen AF, Tan TL, Maltenfort MG, Kucukdurmaz F, Parvizi J: The Incidence and Economic Burden of InHospital Venous Thromboembolism in the United States. J Arthroplasty 2017, 32(4):1063-1066.

4. Courtney PM BA, Levine BR, Sheth NP, Paprosky WG: Are revision hip arthroplasty patients at higher risk for venous thromboembolic events than primary hip arthroplasty patients? The Journal of Arthroplasty (2017) 2017, doi: 10.1016/j.arth.2017.07.028.

5. Deirmengian GK, Heller S, Smith EB, Maltenfort M, Chen AF, Parvizi J: Aspirin Can Be Used as Prophylaxis for Prevention of Venous Thromboembolism After Revision Hip and Knee Arthroplasty. J Arthroplasty 2016, 31(10):22372240.

6. Wu YG, Zeng Y, Yang TM, Si HB, Cao F, Shen B: The Efficacy and Safety of Combination of Intravenous and Topical Tranexamic Acid in Revision Hip Arthroplasty: A Randomized, Controlled Trial. J Arthroplasty 2016, 31(11):2548-2553.

7. Warren JA, Sundaram K, Kamath AF, Molloy RM, Krebs VE, Mont MA, Piuzzi NS: Venous Thromboembolism Rates Did Not Decrease in Lower Extremity Revision Total Joint Arthroplasty From 2008 to 2016. J Arthroplasty 2019, 34(11):2774-2779.

8. Kester BS, Merkow RP, Ju MH, Peabody TD, Bentrem DJ, Ko CY, Bilimoria KY: Effect of post-discharge venous thromboembolism on hospital quality comparisons following hip and knee arthroplasty. J Bone Joint Surg Am 2014, 96(17):1476-1484.

9. Akay OM: The Double Hazard of Bleeding and Thrombosis in Hemostasis From a Clinical Point of View: A Global Assessment by Rotational Thromboelastometry (ROTEM). Clin Appl Thromb Hemost 2018, 24(6):850-858.

10. Konig G, Yazer MH, Waters JH: The effect of salvaged blood on coagulation function as measured by thromboelastography. Transfusion 2013, 53(6):1235-1239.

11. David L. Hepner MC, Kodali Bhavani-Shankar: Coagulation Status Using Thromboelastography in Patients Receiving Warfarin Prophylaxis and Epidural Analgesia. Journal of Clinical Anesthesia 2002, 14:405-410. 
12. Agren A, Wikman AT, Holmstrom M, Ostlund A, Edgren G: Thromboelastography (TEG(R)) compared to conventional coagulation tests in surgical patients-a laboratory evaluation. Scand J Clin Lab Invest 2013, 73(3):214-220.

13. Dai Y, Lee A, Critchley LA, White PF: Does thromboelastography predict postoperative thromboembolic events? A systematic review of the literature. Anesth Analg 2009, 108(3):734-742.

14. Jie Bai1 Q-WZ, Shu-Hong Fu,et al. : Association between thrombelastography system and thromboembolic and bleeding events in Chinese aged people. Int J Clin Exp Med 2013, 6(4):310-319.

15. Louis SG, Van PY, Riha GM, Barton JS, Kunio NR, Underwood SJ, Differding JA, Rick E, Ginzburg E, Schreiber MA: Thromboelastogram-guided enoxaparin dosing does not confer protection from deep venous thrombosis: a randomized controlled pilot trial. J Trauma Acute Care Surg 2014, 76(4):937-942; discussion 942-933.

16. Parameswaran A, Krishnamoorthy VP, Oommen AT, Jasper A, Korula RJ, Nair SC, Poonnoose PM: Is pre-operative assessment of coagulation profile with Thrombelastography (TEG) useful in predicting venous thromboembolism (VTE) following orthopaedic surgery? J Clin Orthop Trauma 2016, 7(Suppl 2):225-229.

17. Wu XD, Chen Y, Tian M, He Y, Tao YZ, Xu W, Cheng Q, Chen C, Liu W, Huang W: Application of thrombelastography (TEG) for safety evaluation of tranexamic acid in primary total joint arthroplasty. J Orthop Surg Res 2019, 14(1):214.

18. Stefan KESSLER SK, Wolfram KÄFER, Wolfhart PUHL, Thomas SCHOCHAT: Influence of operation duration on perioperative morbidity in revision total hip arthroplasty. Acta Orthopædica Belgica 2003, 69(4):328-333.

19. Martinelli I, Bucciarelli P, Mannucci PM: Thrombotic risk factors: basic pathophysiology. Crit Care Med 2010, 38(2 Suppl):S3-9.

20. Hassouna HI: Thrombophilia and hypercoagulability. Med Princ Pract 2009, 18(6):429-440.

21. Krzanicki D, Sugavanam A, Mallett S: Intraoperative hypercoagulability during liver transplantation as demonstrated by thromboelastography. Liver Transp/2013, 19(8):852-861.

22. Goel R, Patel EU, Cushing MM, Frank SM, Ness PM, Takemoto CM, Vasovic LV, Sheth S, Nellis ME, Shaz B et al: Association of Perioperative Red Blood Cell Transfusions With Venous Thromboembolism in a North American Registry. JAMA Surg 2018.

23. Kim Y, Xia BT, Jung AD, Chang AL, Abplanalp WA, Caldwell CC, Goodman MD, Pritts TA: Microparticles from stored red blood cells promote a hypercoagulable state in a murine model of transfusion. Surgery 2018, 163(2):423-429.

24. McCrath DJ, Cerboni E, Frumento RJ, Hirsh AL, Bennett-Guerrero E: Thromboelastography maximum amplitude predicts postoperative thrombotic complications including myocardial infarction. Anesth Analg 2005, 100(6):15761583.

25. Van PY, Cho SD, Underwood SJ, Morris MS, Watters JM, Schreiber MA: Thrombelastography versus AntiFactor Xa levels in the assessment of prophylactic-dose enoxaparin in critically ill patients. J Trauma 2009, 66(6):1509-1515; discussion 1515-1507.

26. Rathbun S, Tafur A, Grant R, Esmon N, Mauer K, Marlar RA: Comparison of methods to determine rivaroxaban antifactor Xa activity. Thromb Res 2015, 135(2):394-397.

27. Hernandez-Juarez J, Espejo-Godinez HG, Mancilla-Padilla R, Hernandez-Lopez JR, Moreno JAA, Majluf-Cruz K, Moreno-Hernández M, Isordia-Salas I, Majluf-Cruz A: Effects of Rivaroxaban on Platelet Aggregation. Journal of Cardiovascular Pharmacology 2020, 75(2):180-184.

28. Falck-Ytter Y FC, Johanson N a, et al.: Prevention of VTE in orthopedic surgery patients: antithrombotic therapy and prevention of thrombosis, 9th ed: American College of Chest Physicians Evidence-Based Clinical Practice Guidelines. Chest 2012, 141(2 Suppl):e278S-325S.

\section{Figures}



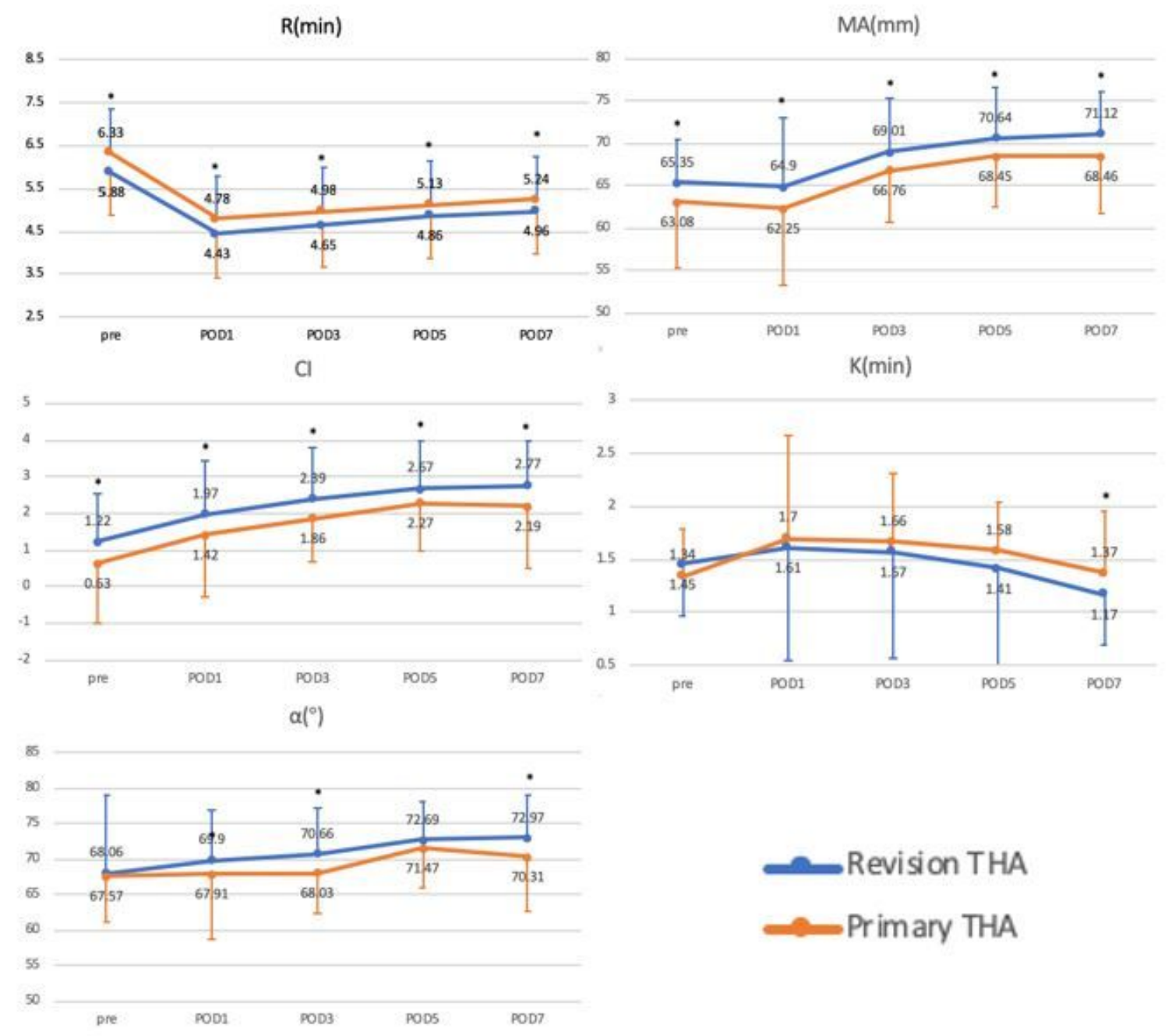

Figure 1

The perioperative TEG parameters ( $R, K$, a-angle and MA values) of THA. The asterisks indicate values that were significantly different between the revision THA and primary THA cohorts.THA total hip arthroplasty, Pre pre-operation, POD1 post-operative day 1, POD3 post-operative day 3, POD5 post-operative day 5, POD7 post-operative day 7. 


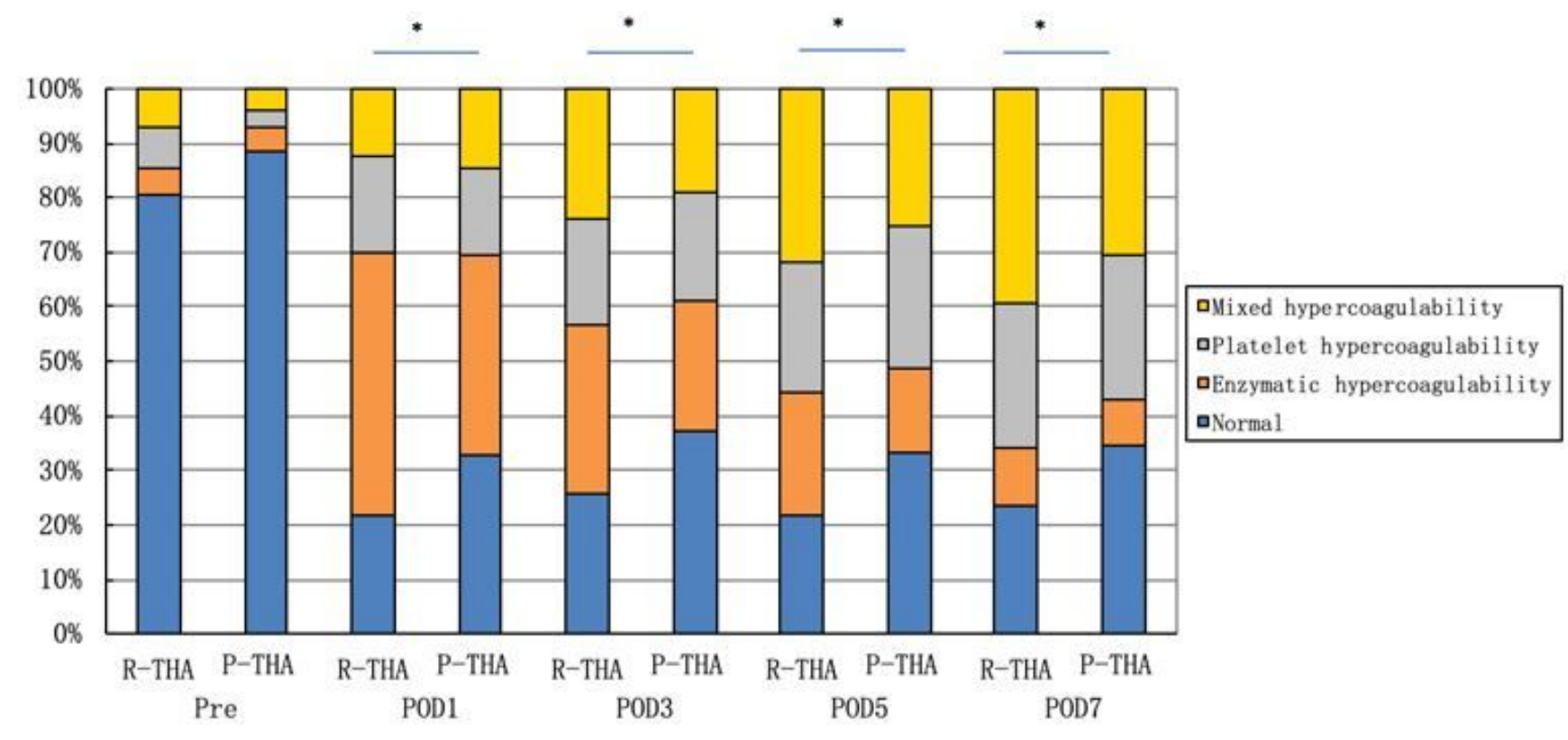

Figure 2

The proportion of different statuses of coagulability at different time points of revision THA and primary THA. Pre preoperation, POD1 post-operative day 1, POD3 post-operative day 3, POD5 post-operative day 5, POD7 postoperative day 7. 